\title{
EDUCAR HACIA UN CORAZÓN INTELIGENTE: INTELIGENCIA EMOCIONAL EN LA NIÑEZ
}

\author{
Mónica Muriel Fernández \\ Educadora Social \\ monica.muriel.f@gmail.com \\ Ana Isabel Isidro de Pedro \\ Universidad de Salamanca \\ anyis@usal.es
}

Recepción Artículo: 26 febrero 2020

Admisión Evaluación: 4 marzo 2020

Informe Evaluador 1: 13 marzo 2020

Informe Evaluador 2: 15 Marzo 2020

Aprobación Publicación: 20 abril 2020

\section{RESUMEN}

En la actualidad, algunos siguen pensando que la Inteligencia Emocional es una rareza 0 un esnobismo inventado desde el ámbito de la educación. Aunque la realidad es bien distinta, dado que las emociones forman parte de nuestra cotidianeidad, las experimentamos constantemente y desde pequeños se enseña a reconocer que son parte de uno mismo y que tenemos que aprender a reconocerlas y vivir con ellas. Por ese motivo, consideramos que es ciertamente importante incidir en la Educación Emocional, tomando las aulas como punto de partida. En definitiva, el Objetivo Principal, y General, del presente trabajado es observar la evolución temporal de la Inteligencia Emocional de niños en un ámbito formal a través de la Educación Emocional. Para ello, se observarán seis componentes: Autoconciencia, Autocontrol, Empatía, Habilidades Sociales, Autoconfianza y Tolerancia a la Frustración en una muestra de niños, estudiantes de Educación Primaria, es decir, de entre 6 y 12 años ( $n=140)$, utilizando para ello una metodología cualitativa de elaboración propia y diseñada ad hoc.

Palabras clave: educación emocional; inteligencia emocional; desarrollo; evolución temporal; educación primaria

\section{ABSTRACT}

Educating towards a smart heart: Emotional Intelligence in the childhood. Nowadays, some still think that Emotional Intelligence is a rarity or snobbery invented from the sphere of education. Although the reality is quite different, because emotions are part of our daily lives, we experience them constantly and since childhood we are taught to recognize that they are part of one and that we have to learn to recognize and live with them. For this reason, we consider that it is certainly important to emphasize the Emotional Education, taking the classrooms as the starting point. In conclusion, the Main and General Objective of the present work is to observe the temporal 


\section{EDUCAR HACIA UN CORAZÓN INTELIGENTE: INTELIGENCIA EMOCIONAL EN LA NIÑEZ}

evolution of the Emotional Intelligence of children in a formal setting through the Emotional Education. For that, six components will be observed: Self-awareness, Self-regulation, Empathy, Social Skills, Self-confidence and Tolerance to Frustration, in a sample $(n=140)$ of schoolchildren of Primary Education, that is, between 6 and 12 years old, using for it a qualitative methodology of self-elaboration and designed ad hoc.

Keywords: emotional education; emotional intelligence; development; temporal evolution; primary education

\section{MARCO TEÓRICO}

En las últimas décadas hemos sido testigos de cómo la sociedad ha ido evolucionando en ámbitos como la tecnología, la sanidad, etc. Sin embargo, hay otros en donde el cambio no se ha producido al mismo nivel o no es tan visible. Uno de estos aspectos, que podemos considerar actualmente en crisis, son los valores. Aunque "la preocupación por el tema de los valores en educación no es algo nuevo" (Froufe Quintas, 1990, p. 111), ésta se ha visto incrementada por las grandes crisis económicas y sociales que la población ha atravesado en los últimos años. Aun así, no podemos, ni debemos, caer en el pensamiento fácil de que las nuevas generaciones están perdidas.

Las familias, desde siempre, han sido las encargadas de la educación de los hijos y de la transmisión de ciertos valores sociales. Sin embargo, encontramos que esto está cambiando y están siendo los centros educativos quienes, en muchos casos, están supliendo estas carencias. Bien es cierto que es injusto generalizar, pero es algo que ocurre en numerosas familias actuales.

Esta crisis de valores también se ve reflejada en la conducta actual de muchos menores dado que los problemas que suelen advertirse de forma más frecuente en los centros educativos son "disrupción en las aulas, conflictos entre profesorado y alumnado, bullying, vandalismo y daños materiales, conflicto multicultural, etc." (Martínez Otero, 2005, pp. 39-42, citado por Domínguez Ramos, 2017, p. 14). Para afrontar y prevenir este tipo de problemáticas, Domínguez Ramos (2017) apunta que sería positivo trabajar la educación emocional desde los propios centros educativos, no centrándose exclusivamente en los conocimientos establecidos en el curriculum, para conseguir soluciones más duraderas y un mayor conocimiento y control emocional.

En definitiva, se trata del desarrollo de la inteligencia emocional que tiene como base las inteligencias inter e intrapersonal (Palacios, 2010), mediante la cual "se espera que el individuo pueda ser efectivo cuando esté ante un escenario que amerite control emocional o control de impulsos para actuar ante situaciones de ira, miedo, sorpresa..." (Palacios, 2010, p. 252). Por ello, al profesorado actual no solo se le pide que imparta las materias correspondientes al nivel educativo, sino que también se ocupe del mundo emocional de sus alumnos. Ello conlleva "comprender a los estudiantes, interesarse por su mundo de la vida, por su espacio vital: es decir, por lo que viven, por lo que sienten" (Palomero, 2005, p. 10). En definitiva, podríamos decir que "la inteligencia emocional es uno de los fundamentos y uno de los objetivos de la educación emocional: formar personas emocionalmente inteligentes" (Bisquerra, 2011, p. 5).

Y es también Bisquerra (2016) el que define la Educación Emocional como "una respuesta a las necesidades sociales que no están suficientemente atendidas en el currículum académico ordinarios" (p. 11). Respecto a los contenidos que abarca la educación emocional (Bisquerra, 2011) menciona que pueden variar según las personas a las que esté destinada. Esto ocurre dado que influye el nivel educativo, los contenidos previos que se tengan, la madurez, las características personales y muchos otros factores que se deben tener en cuenta. Igualmente, considera a la Inteligencia Emocional, las Competencias Emocionales, las Inteligencias Múltiples, el Bienestar y la Emoción contenidos propios de la Educación Emocional.

Pero, ¿qué son las emociones? Podríamos definirlas como un tipo de respuesta que produce nuestro organismo a estímulos, tanto internos como externos. Pero ante un mismo estímulo, las personas pueden generar muy diversos tipos de respuesta (Bisquerra, 2009). Y podemos diferenciarlas de los sentimientos en que las emociones son "básicas, primitivas y unidireccionales", mientras que los sentimientos van ligados al razonamiento, al cómo pensamos que nos sentimos. Por lo que, en definitiva, las emociones ocurren de forma inconsciente, al 
contrario que los sentimientos que tienen lugar de una forma mucho más consciente. Y, además, aquellas se dan de forma previa al sentimiento: "sin emoción no hay sentimiento" (Reyes, 2016, párr. 4).

\section{OBJETIVOS}

La presente investigación se ha desarrollado con el Objetivo Principal de conocer la evolución de Inteligencia Emocional en los niños tomando las aulas como punto de partida. Esta decisión se toma teniendo como horizonte la importancia de incidir en la educación emocional como base para resolver situaciones problemáticas que pueden producirse en las aulas.

Pero también se establecieron una serie de Objetivos Específicos que consistían en la identificación y el análisis las habilidades sociales, empatía, tolerancia a la frustración, autoconocimiento, autocontrol y autoconfianza.

\section{MUESTRA}

Ante la dificultad de llegar a una gran muestra de miembros de la población considerada de interés, se tomó la decisión de llevar a cabo la investigación solo en un centro de Educación Formal. Dicho centro se encuentra en la localidad extremeña de Cáceres.

La muestra fue seleccionada a través de una técnica de muestreo incidental, por lo que es no probabilística, ya que las aulas fueron asignadas por el centro y, por tanto, no habían sido elegidos de forma previa. Las edades de los participantes oscilaban entre los 6 y los 12 años, siendo todos alumnos de Educación Primaria.

El total de alumnos evaluados fue de $n=106$, de los cuales 68 eran de género femenino y 72 , masculino; cursando 21 primero, 22 segundo, 24 tercero, 26 cuarto, 22 quinto y los 25 restantes sexto de Primaria. Sobre sus edades podemos señalar que 13 alumnos tienen seis años (9.28\%), 19 tienen siete (13.57\%), de ocho años encontramos 32 (22.86\%), de nueve 23 (16.43\%), 22 estudiantes cuentan con diez años (15.71\%), 27 once (19.29\%) y los 4 restantes tienen doce años.

\section{METODOLOGíA}

Para realizar nuestra investigación, utilizamos una metodología cualitativa de elaboración propia y diseñada ad hoc plasmada en una encuesta ${ }^{1}$. Esta decisión se tomó teniendo muy en cuenta la edad de los participantes de la muestra para una total comprensión de los ítems.

La encuesta (ver Tabla 1) está organizada en seis subescalas: autoconciencia, autocontrol, empatía, habilidades sociales, autoconfianza y tolerancia a la frustración. En el caso de los alumnos de $1^{0}, 2^{0}$ y $3^{0}$ de Educación Primaria, cada subescala está compuesta por dos preguntas, exceptuando la autoconciencia y la autoconfianza, que están medidas por cinco preguntas y una, respectivamente. Mientras que para los estudiantes de $4^{0}, 5^{\circ}$ y $6^{0}$ se seleccionaron algunas de las preguntas (señaladas con *), quedando las subescalas representadas con una pregunta cada una, exceptuando el autocontrol que constaba de dos. Se tomó esta decisión teniendo en cuenta que, debido a una mayor edad y madurez, las respuestas serían más extensas, pretendiendo evitar la desconcentración y, por ende, obtener resultados menos fiables. 


\section{EDUCAR HACIA UN CORAZÓN INTELIGENTE: INTELIGENCIA EMOCIONAL EN LA NIÑEZ}

Tabla 1. Ítems, por subescalas, de las encuestas de Educación Primaria.

\begin{tabular}{|c|} 
AUTOCONCIENCIA \\
$\begin{array}{c}\text { Ítem 3. Desde que se ha levantado, Dani ha tenido diferentes emociones, } \\
\text { ¿cuál estás sintiendo tú ahora mismo? Rodéala y descríbela, ¿Qué sientes? ¿Qué } \\
\text { piensas? }{ }^{*}\end{array}$ \\
\hline Ítem 11. Me da asco... \\
\hline Ítem 12. Estoy triste si... \\
\hline Item 13. Me sorprendo con... \\
Ítem 14. Me alegra... \\
\hline AUTOCONTROL
\end{tabular}

Ítem 9. ¿Qué cosas te hacen sentir mejor y que el enfado se te pase más rápido? * Ítem 10. ¿Cómo te comportas? *

\section{EMPATÍA}

Ítem 1. ¡Ay! De repente a Dani le ha pasado algo, ¿cómo crees que se siente? ¿Cómo has adivinado lo que siente? ¿Qué crees que le puede haber pasado?

Ítem 6. Pero, al igual que Dani, estos niños también están sintiendo emociones. ¿Sabrías decir qué emoción sienten?*

\section{HABILIDADES SOCIALES}

Item 4. Dani ha quedado en el parque con su amiga Candela para saltar a la comba.

De repente aparece un compañero de clase, Juan, al que Candela no conoce y que también quiere jugar con ellos. ¿Cómo los presentarías? Item 5. Dani, Juan y Candela suelen pasar la tarde juntos, pero ¿están teniendo un buen comportamiento? ¿Quién no? ¿Por qué? *

\section{AUTOCONFIANZA}

Item 2. En clase, el profesor de Dani les hace una pregunta a todos y Dani puede reaccionar de diferentes formas. ¿Con cuál de estas reacciones de Dani te sientes más identificado? Rodéalo. Pero ¿por qué con ese y no con otro?*

\section{TOLERANCIA A LA FRUSTRACIÓN}

Ítem 7. Parece que hoy Dani tenía examen de matemáticas y se le ha olvidado el estuche en casa, pero el examen ya ha empezado ¿qué puede hacer?

Ítem 8. Al salir del colegio se pone a llover y Dani, aunque lleva paraguas, se está mojando porque no consigue abrirlo, ¿qué puede hacer?* 
Se alternaron dibujos, de muy laboriosa pero gratificante elaboración propia, y fotografías, para observar si el reconocimiento de expresiones emocionales resultaba más sencillo en caras infantiles dibujadas o fotografiadas. De igual forma, se optó por diseñar un protagonista de género sin definir y con un nombre neutro para que los alumnos pudieran sentirse más identificados (ver Figura 1).

Figura 1. Representación de Dani.

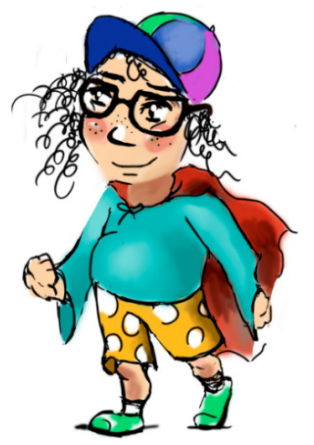

Para tener lugar la aplicación del instrumento a la muestra seleccionada se solicitó el consentimiento del colegio. Dicha aplicación se llevó a cabo de forma grupal por clases. Para ello, fueron seleccionadas, de forma aleatoria, un aula de cada curso. La duración de realización de cada encuesta alcanzó en algunos casos los treinta minutos, pero nunca fue superior.

\section{RESULTADOS Y DISCUSIÓN}

El proceso de análisis se ha llevado a cabo a través del programa Excel. Estos resultados están reflejados en gráficos con los que se busca favorecer la comprensión. Se irá analizando por subescalas, empezando por las comunes y continuando con las específicas para $1^{0}, 2^{\circ}$ y $3^{0}$ de Primaria.

En primer lugar, empezamos analizando los resultados obtenidos de la subescala de Autoconciencia que, tal y como podemos ver en la Figura 2, la emoción más elegida fue Alegría, con un 76\%, seguida de Sorpresa, con un $13 \%$.

Figura 2. Resultados a la pregunta 3: ¿Qué sientes?

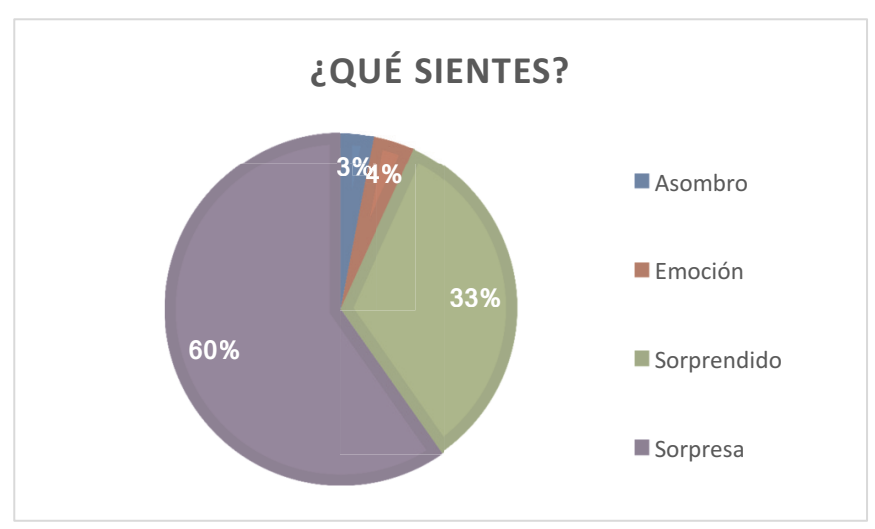




\section{EDUCAR HACIA UN CORAZÓN INTELIGENTE: INTELIGENCIA EMOCIONAL EN LA NIÑEZ}

En cuanto al resto de preguntas, observamos que "me da asco... "obtuvo la mayor coincidencia de respuesta en los gusanos, las cucarachas y la caca en primero de Educación Primaria. En segundo, destaca la caca y en tercero, las verduras y la caca. Por tanto, la respuesta más elegida fue la caca, por un total de 14 alumnos.

La pregunta "estoy triste si...", obtuvo coincidencia de respuesta en primero y tercero de Educación Primaria, donde 10 alumnos de cada curso optaron por responder con un me insultan. En cambio, en segundo, me hacen Ilorar fue la respuesta más elegida, siendo también 10 el número de sujetos que se decantaron por esta contestación.

Por último, encontramos la pregunta de "me sorprendo con..." la cual en los tres cursos de Primaria la mayor respuesta escogida por los alumnos, haciendo un total de 29, ha sido regalos, seguida de mi cumple, tan solo escogida por 7 estudiantes.

Continuamos analizando las subescalas; en la de Autocontrol (ver Figura 3) encontramos que un $29 \%$ de Ios alumnos de Educación Primaria encuestados, aseguran sentirse mejor y que les ayuda a que se les pase antes el enfado el hecho de estar con sus amigos y sus padres. Estando 11 puntos por debajo la segunda y tercera respuesta con mayor porcentaje de coincidencias (18\%), siendo éstas jugar y jugar con mis amigos.

Figura 3. Respuesta a la pregunta 9: ¿Qué cosas te hacen sentir mejor y que el enfado se te pase más rápido?

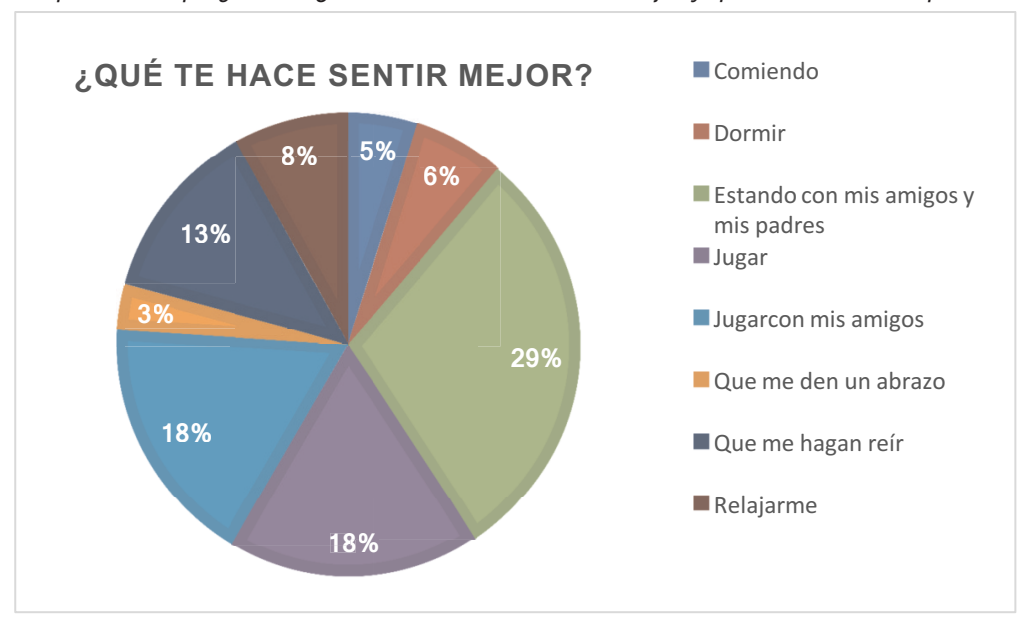

Respecto al comportamiento (ver Figura 4), la respuesta me porto bien podemos observar que es representativa del 29\% del alumnado de Educación Primaria encuestado que respondió a la pregunta "¿cómo te comportas?" El 20\% y, por tanto, la segunda contestación más repetida, fue me porto regular; seguida de cerca por me porto un poco mal, que representa al $17 \%$ de los estudiantes de Primaria. 
Figura 4. Resultados a la pregunta 10: ¿Cómo te comportas?

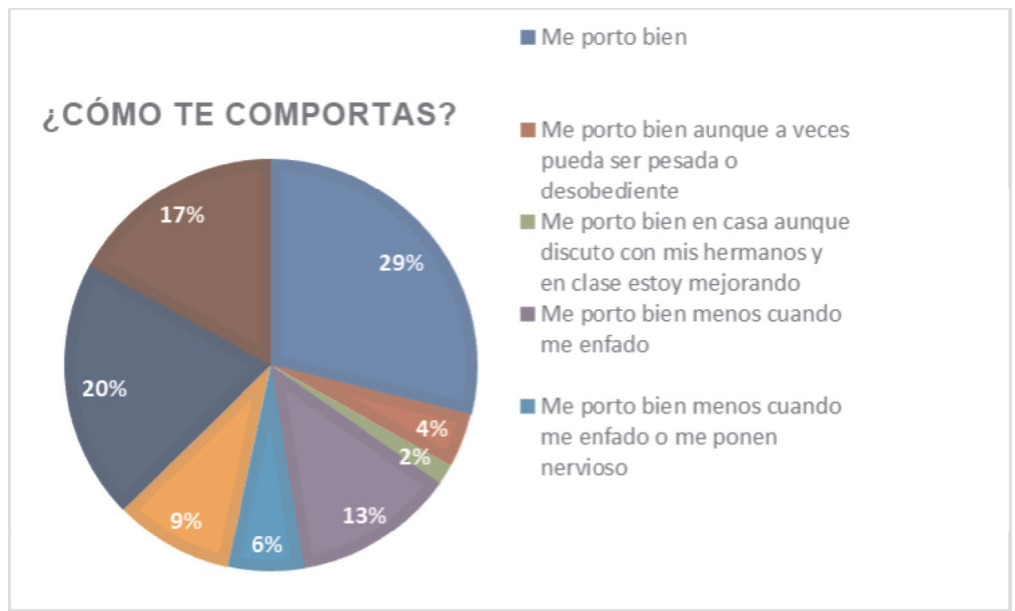

Respecto a la subescala de Empatía podemos constatar, a través de la Figura 5, que en la primera imagen presentada (A), el 60\% de los participantes encuestados saben tanto identificar de forma correcta el tipo de emoción como darle el nombre correcto, dado que definen la emoción de la fotografía como sorpresa. Aunque también Ilama la atención que haya un 33\% de los niños que ante la pregunta "¿qué emoción siente?", utilicen el adjetivo (en este caso sería sorprendido) para referirse a la emoción que están observando.

La segunda imagen que se les presenta (B) la podemos analizar a través de la Figura 6 y podemos comprobar que, de nuevo, con un 59\%, los alumnos identifican la alegría con la fotografía, mientras que un $21 \%$ vuelve a utilizar el adjetivo para referirse a la emoción correspondiente.

Figura 5. Resultados a la pregunta 6: ¿Sabrías decir qué emoción siente?

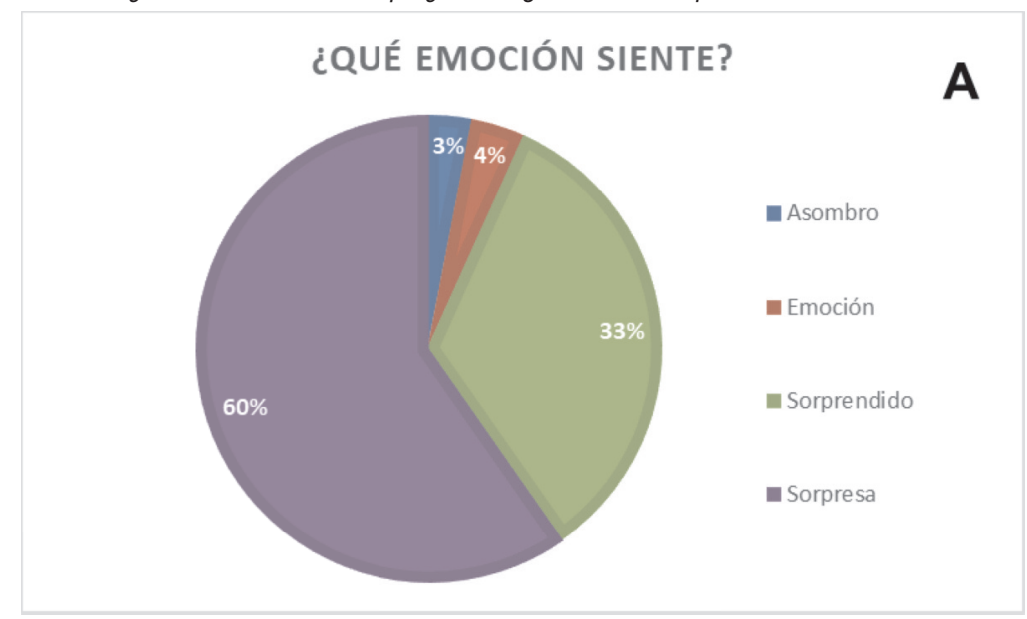




\section{EDUCAR HACIA UN CORAZÓN INTELIGENTE: INTELIGENCIA EMOCIONAL EN LA NIÑEZ}

Figura 6. Resultados a la pregunta 6: ¿Sabrías decir qué emoción siente?

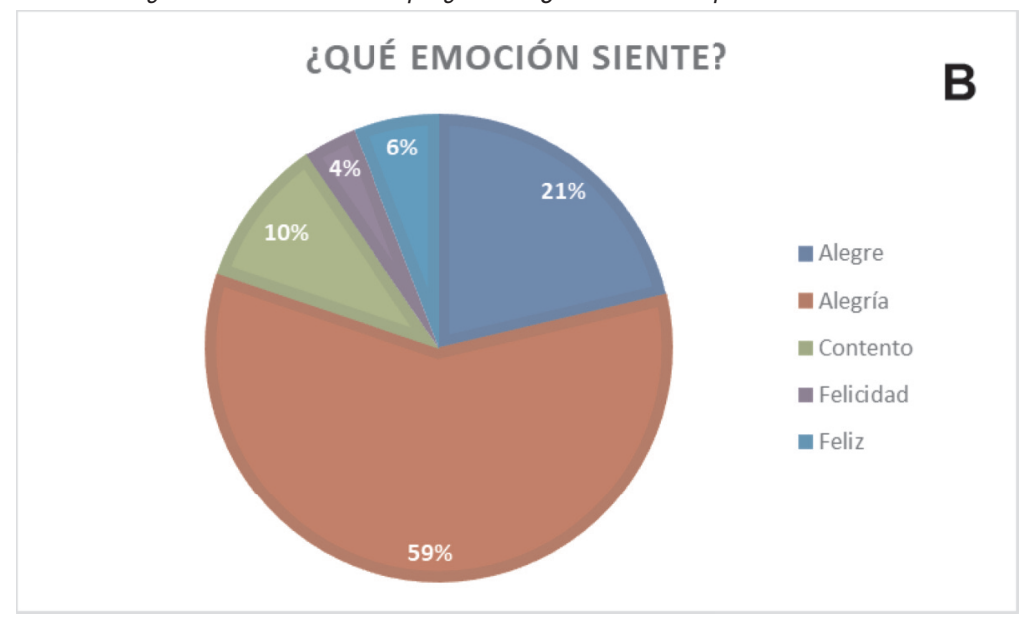

Respecto al resto de preguntas pertenecientes a primero, segundo y tercer curso encontramos "¿cómo crees que se siente?", a la que el $68 \%$ de la muestra responde con el sustantivo tristeza, seguida de lejos por el $18 \%$ que se decanta por mal. También encontramos la pregunta "¿cómo has adivinado lo que siente?", a la que el 49\% dice haberse dado cuenta porque Ilora o el 30\% porque tiene cara de tristeza. Por último, un $34 \%$ y un $24 \%$ responden con que se ha caído y que alguien no quería jugar con él, respectivamente, a la pregunta de "¿qué le puede haber pasado?".

En cuarto lugar, analizaremos la subescala de Habilidades Sociales, donde encontramos la pregunta 5 representada en tres imágenes, que hemos llamado A, B y C.

En la imagen A (ver Figura 7), el 64\% de los alumnos señalaron que Dani tira del pelo a Candela, seguida de un $21 \%$ que lo expresaron como que Dani estaba teniendo un mal comportamiento. Aunque hubo un $4 \%$ que señalaba el mal comportamiento en Candela, repartido este porcentaje entre que Candela no quiere jugar con Dani (2\%) y que Candela imita a Dani (2\%).

Figura 7. Resultados a la pregunta: ¿Esta Dani haciendo algo malo? ¿El qué?

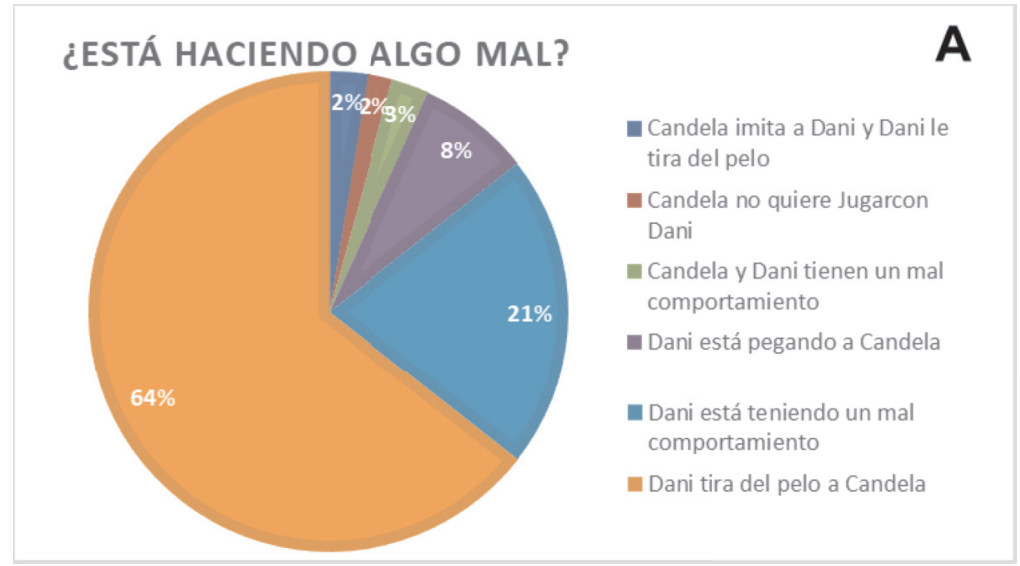


Sobre la imagen B, cabe señalar que el 100\% del alumnado indicó que el comportamiento de Dani estaba siendo el adecuado (ver Figura 8).

Figura 8. Resultados a la pregunta: ¿Esta Dani haciendo algo malo? ¿El qué?

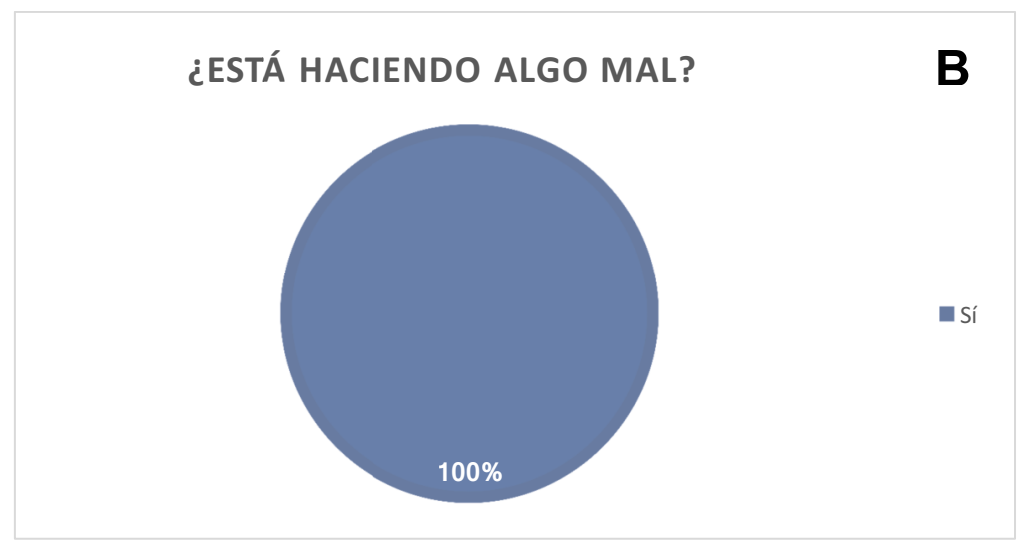

Por último, en la imagen C, el 34\% indicó que Dani empuja a Juan y el 28\%, que Dani está pegando a Juan (ver Figura 9).

Figura 9. Resultados a la pregunta: ¿Esta Dani haciendo algo malo? ¿El qué?

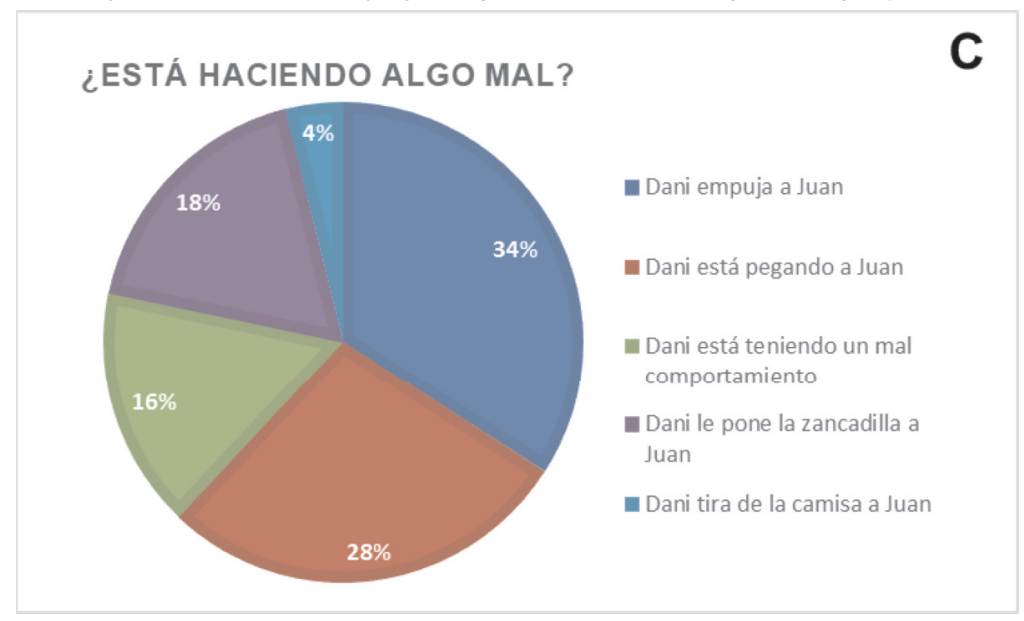

Terminamos de analizar la subescala con la pregunta "icómo lo presentarías?" Encontramos que el $41 \%$ lo definieron como forma de presentación introducir a Juan con un hola, él es Juan. Seguido de él es Juan y ella Candela, con un $27 \%$.

En quinto lugar, analizaremos la Autoconfianza, representada por "¿con cuál de estas reacciones te sientes más identificado?" A lo que un 40\% respondió que con la imagen A, pero seguida muy de cerca, con un 39\%, con la imagen C (ver Figura 10). 


\section{EDUCAR HACIA UN CORAZÓN INTELIGENTE: INTELIGENCIA EMOCIONAL EN LA NIÑEZ}

Figura 10. Resultados a la pregunta 2: ¿Con cuál de estas reacciones te sientes más identificado?

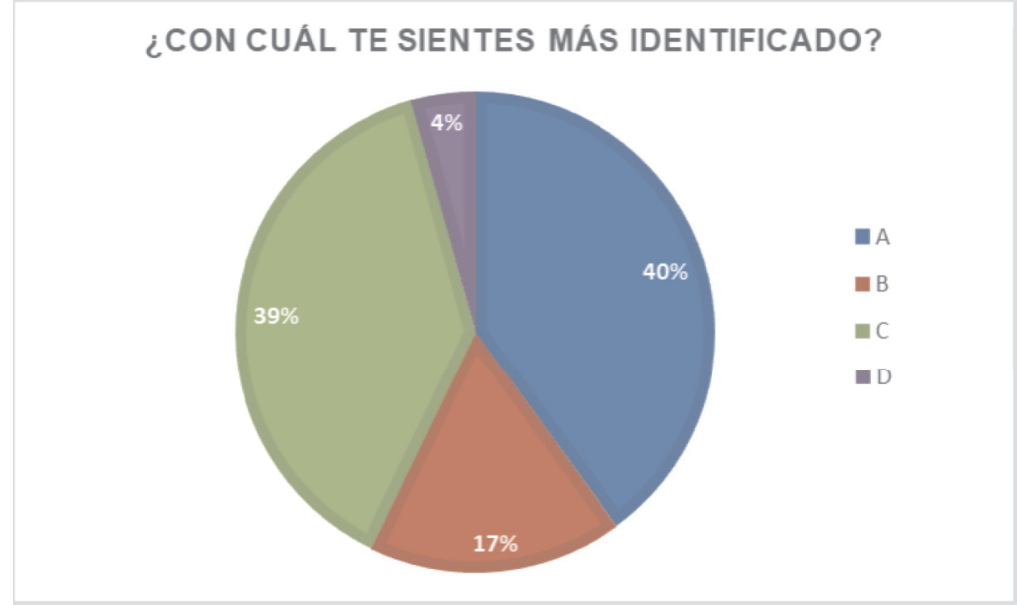

Por último, finalizaremos este análisis de datos cualitativos con la subescala de Tolerancia a la Frustración representada para toda Primaria con la pregunta “qué puede hacer para no mojarse?" En la Figura 11 podemos ver que el $31 \%$ de las respuestas se corresponde con pedir ayuda a un adulto y que, en segundo lugar, con un 23\%, estaría la opción de refugiarse hasta que pare de llover.

Figura 11. Resultados a la pregunta 8: ¿Qué puede hacer para no mojarse?

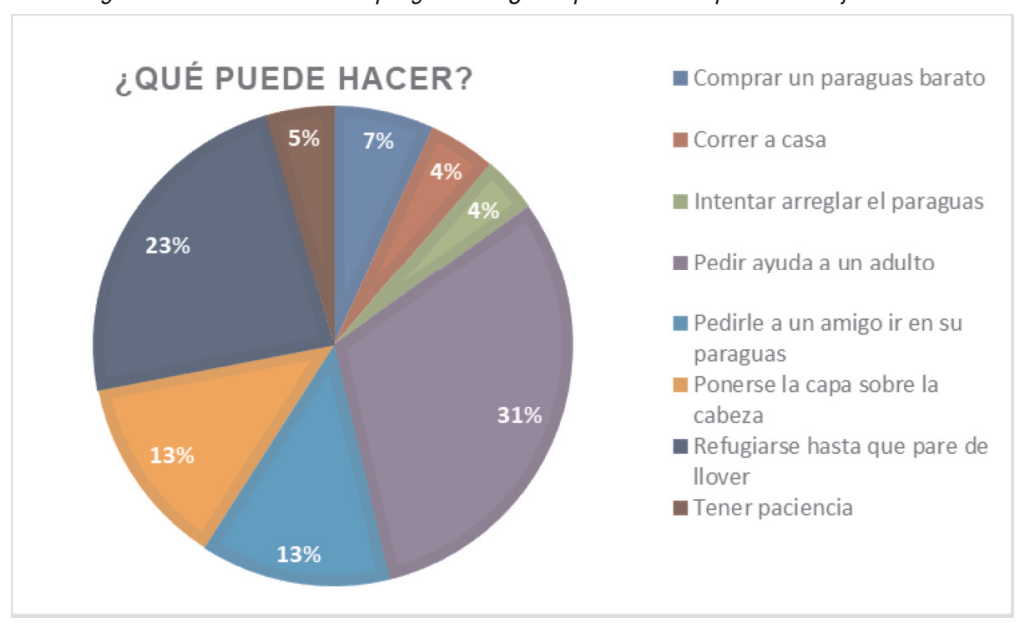

En último lugar analizaremos la pregunta ¿qué puede hacer para escribir?" En la que obtuvo un mayor porcentaje la respuesta de pedírselo a un compañero, con un $46 \%$, y en pedirle uno al profesor, con un $43 \%$,

A continuación, se procederá a un análisis individual de las preguntas, diferenciando así los diferentes resultados obtenidos por curso. Si procedemos al desglose en la Autoconciencia (ver Figura 12), encontramos que la emoción Sorpresa fue más elegida en tercero y cuarto de Primaria, y que está ausente en los niños de primero; o que la emoción de Miedo solo fue elegida por un alumno que cursaba quinto curso. De igual forma, el Enfado solo aparece en primero y segundo; la Vergüenza en segundo, cuarto y sexto de Educación Primaria. 
Figura 12. Resultados a la pregunta 3, por cursos.

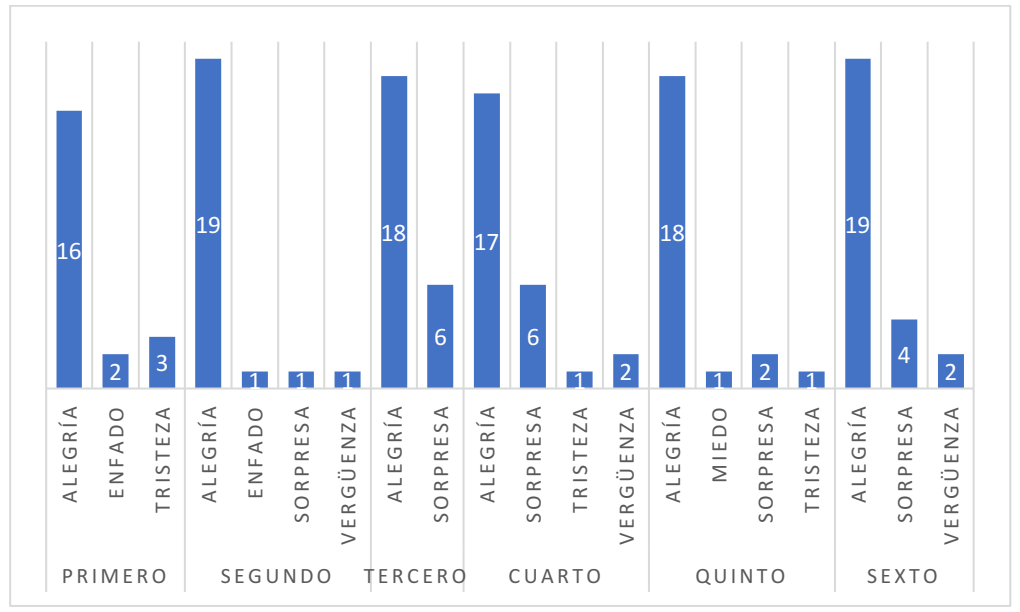

Por lo que se refiere a las justificaciones (ver Figura 13), encontramos que la respuesta más repetida de aquéllos que eligieron la emoción Alegría es que están alegres por estar con mis amigos, ya que se dio en 41 alumnos. Respecto a la sorpresa, 17 señalan que no sabía que iba a pasar esto.

Figura 13. Respuestas a la pregunta 3

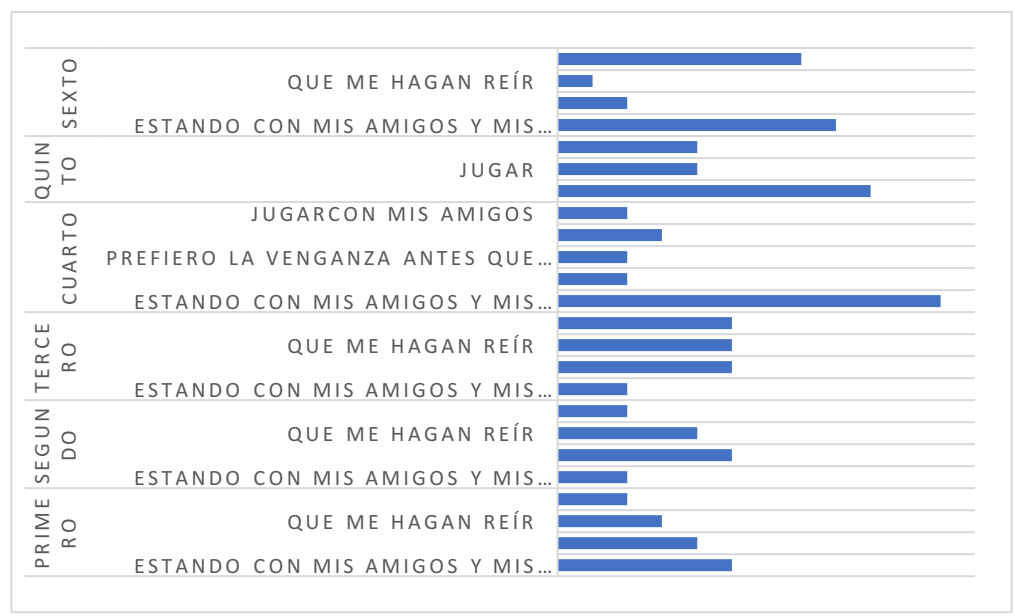

Si analizamos los resultados por cursos de la subescala de Autocontrol, vemos en la Figura 14 que, en primero, cuarto, quinto y sexto, estando con mis amigos y mis padres fue la opción más respondida por los alumnos. Algo que no sucede en segundo, donde jugar ha sido la respuesta más veces repetida; ni en tercero, donde se produce un empate entre jugar, que me hagan reír y jugar con mis amigos. 


\section{EDUCAR HACIA UN CORAZÓN INTELIGENTE: INTELIGENCIA EMOCIONAL EN LA NIÑEZ}

Figura 14. Resultados a la pregunta 9 (¿Qué cosas te hacen sentir mejor y que el enfado se te pase más rápido?) por cursos.

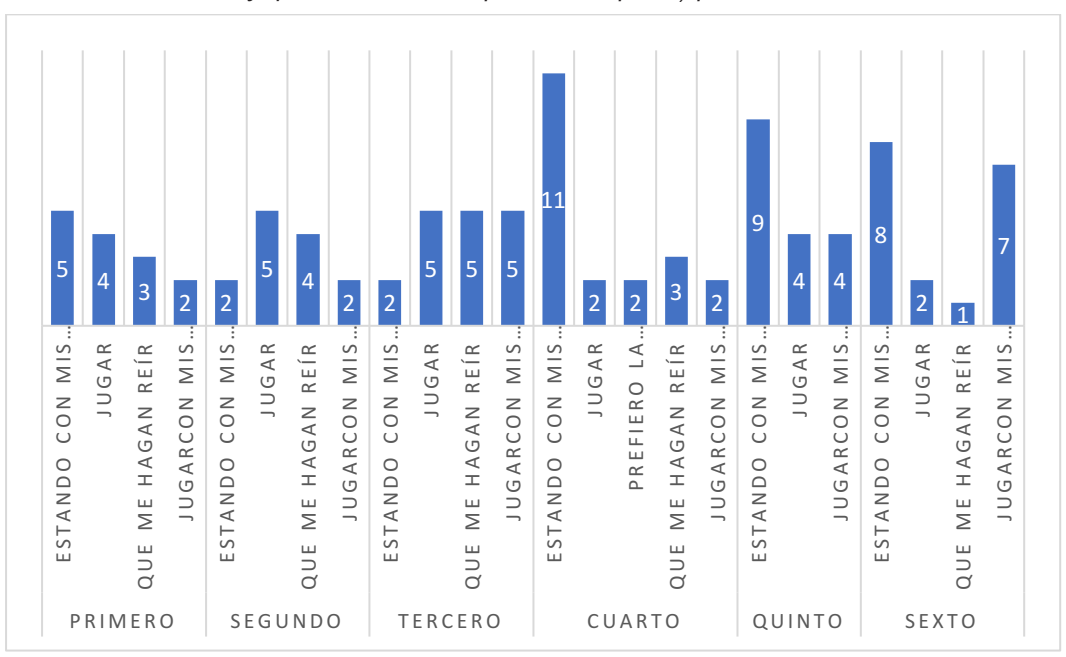

Respecto a la segunda pregunta que encontramos en esta subescala (ver Figura 15), encontramos que me porto bien es la más elegida por los alumnos de tercero, cuarto, quinto y sexto de Primaria. En primero es me porto un poco mal y en segundo, me porto regular.

Figura 15. Resultados a la pregunta 10 (¿Cómo te comportas?) por cursos.

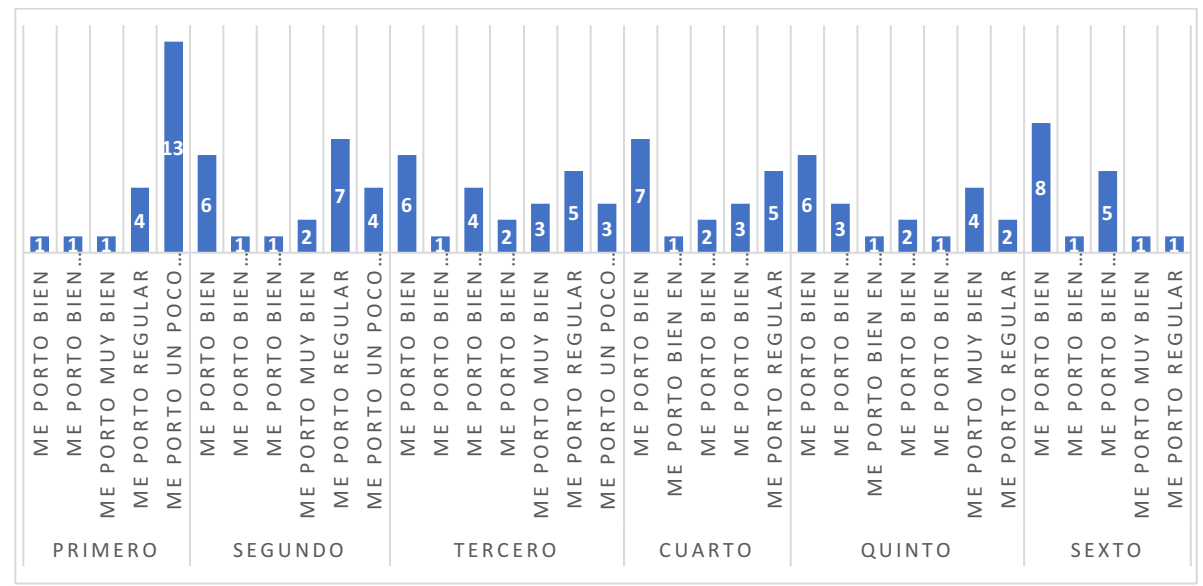

En nuestra tercera subescala, Empatía, al analizar las respuestas (ver Figura 16 y Figura 17), encontramos que tan solo en primero de Primaria sorprendido obtiene un resultado superior a sorpresa, lo mismo que ocurre con alegre en vez de alegría. 
Figura 16. Resultados a la pregunta 6 por cursos.

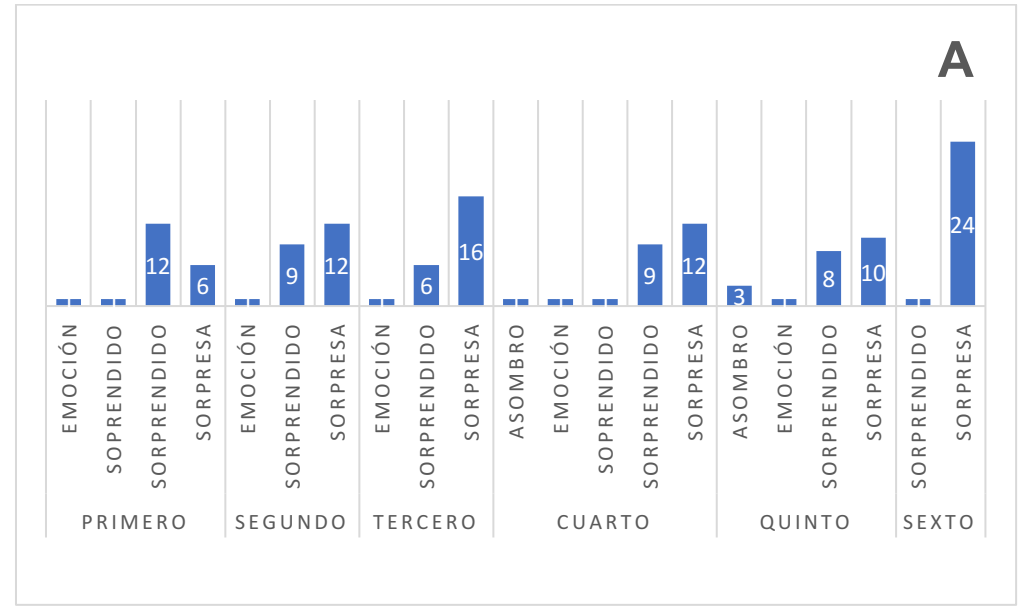

Figura 17. Resultados a la pregunta 6 por cursos.

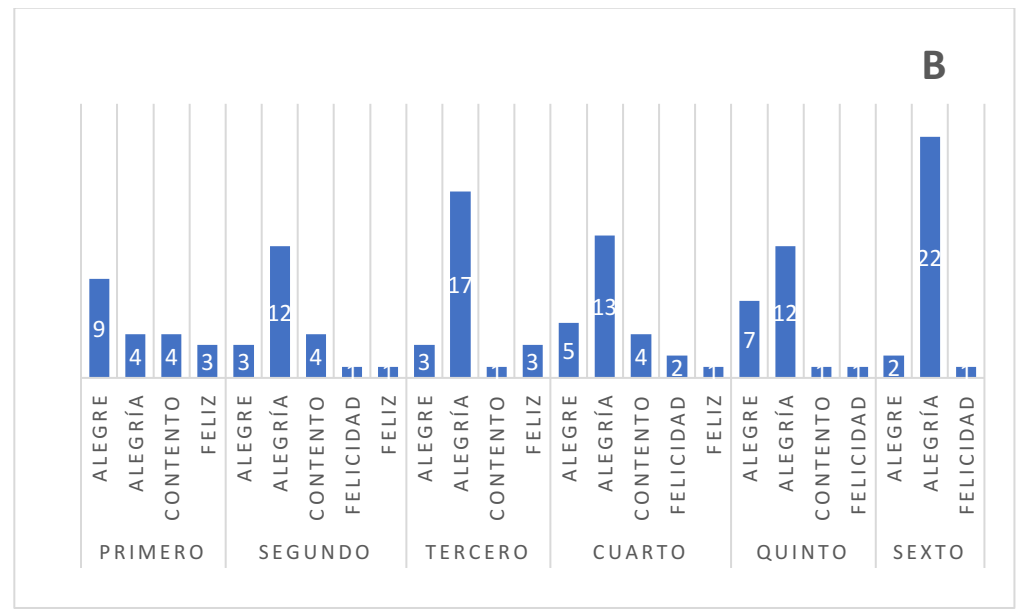

Respecto a las Habilidades Sociales podemos mencionar que en todos los cursos la respuesta más repetida por los estudiantes para la imagen A es Dani tira del pelo a Candela (ver Figura 18). 
Figura 18. Resultados a la pregunta 5 por cursos.

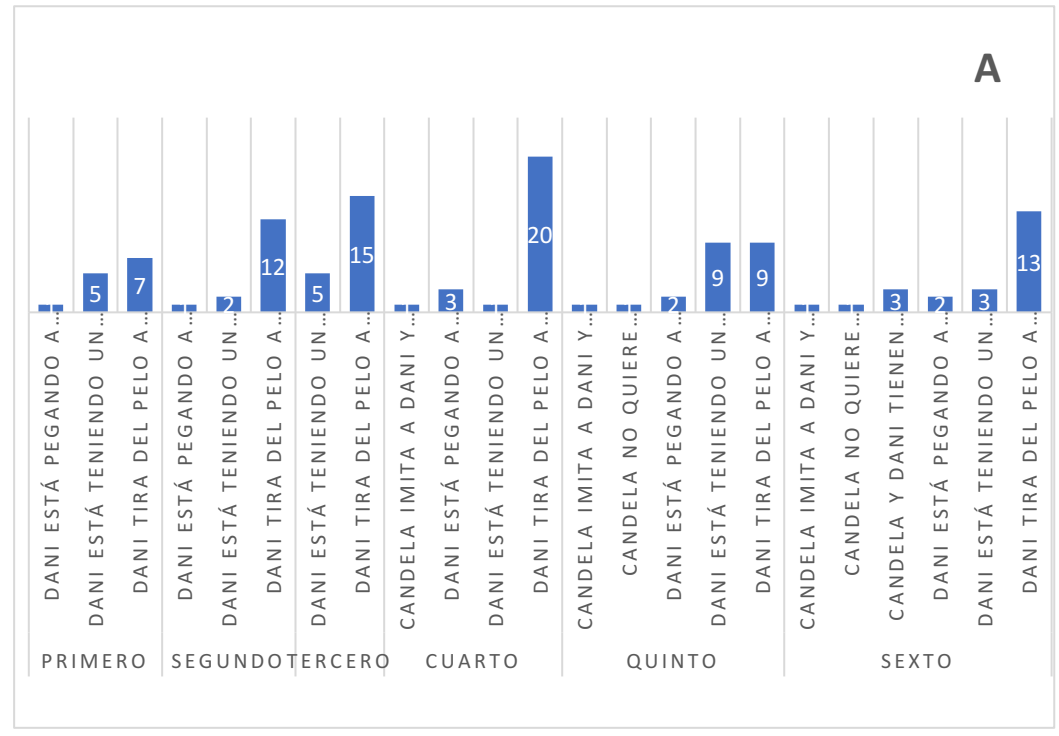

Por lo que se refiere a la C (ver Figura 19), se da una mayor diversidad de resultados. En primero y quinto se produce un empate entre Dani empuja a Juan y Dani está teniendo un mal comportamiento. En segundo y tercero, la respuesta más escogida es Dani empuja a Juan; mientras que en cuarto y sexto se trata de Dani está pegando a Juan.

Figura 19. Resultados a la pregunta 5 por cursos.

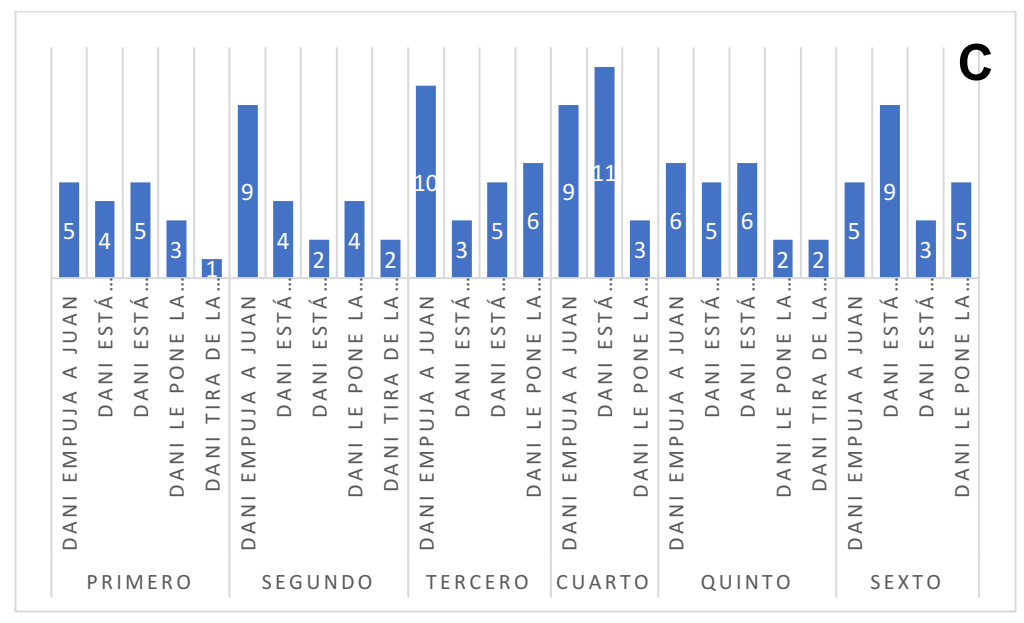

Si desglosamos por cursos la pregunta en común sobre la Autoconfianza, tal y como aparece en la Figura 20, encontramos que en los seis cursos la respuesta más veces reflejada es porque soy muy participativo. 
Figura 20. Resultados a la pregunta 2 por cursos.

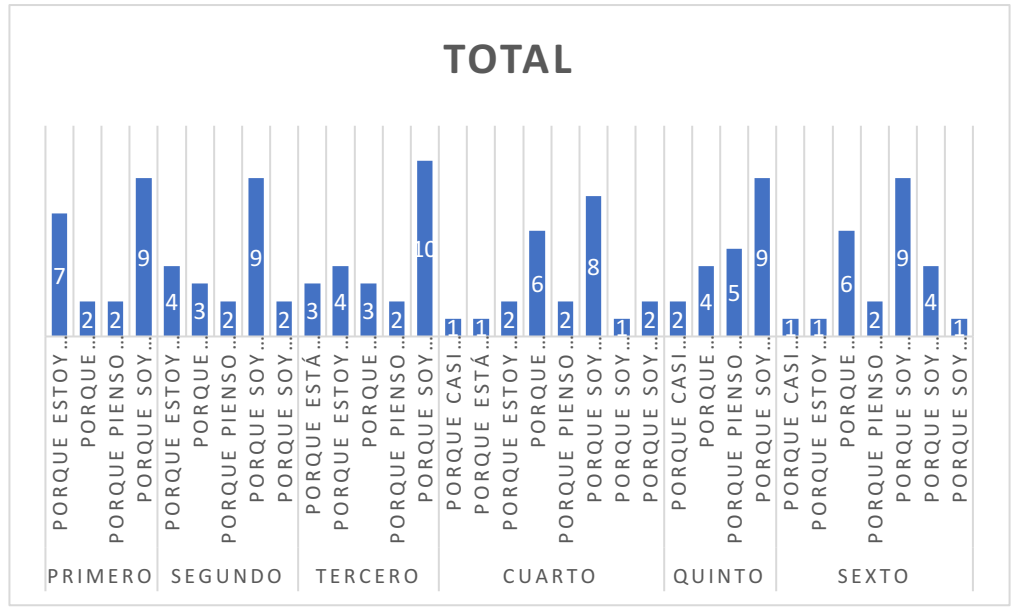

Por último, encontramos la subescala de Tolerancia a la Frustración. Al analizar los datos obtenidos por cursos (ver Figura 21) encontramos que, en primero, segundo, tercero y quinto, la respuesta más repetida por los alumnos es pedir ayuda a un amigo. Aunque no ocurre lo mismo con cuarto y sexto curso donde la más repetida es refugiarse hasta que deje de llover.

Figura 21. Resultados a la pregunta 8 por cursos

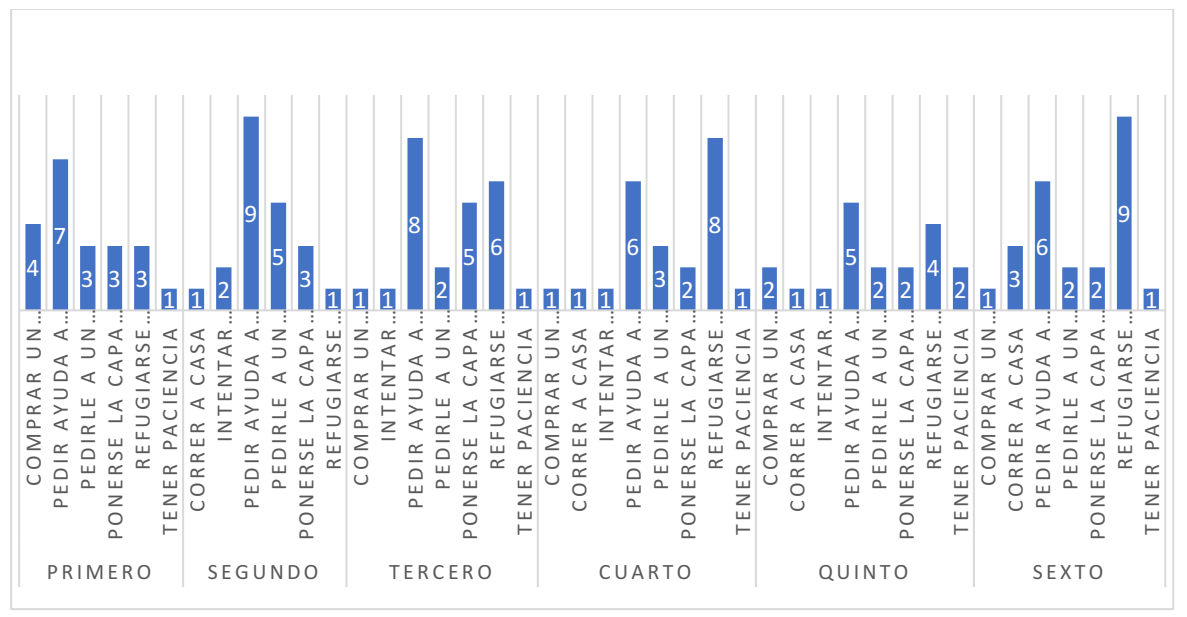

\section{CONCLUSIONES}

La educación emocional es muy amplia y podemos encontrar diversos contextos desde los que se trabaja. Para Domínguez Ramos (2017) lo que se debe conseguir, y para lo que se debe trabajar, es crear un modelo de trabajo que incluya de igual forma tanto el trabajo desde los centros educativos como desde la sociedad, dado que es "un error identificar de manera excesiva educación con educación escolar" (Petrus, 2004, p. 90). 


\section{EDUCAR HACIA UN CORAZÓN INTELIGENTE: INTELIGENCIA EMOCIONAL EN LA NIÑEZ}

La Educación Emocional "se considera fundamental y es una tarea que se debe realizar desde la etapa de la educación primaria” (Ambrona, López y Márquez, 2012; Carpena, 2003; Ruiz, Roca y Castillo, 2002; Vadebencoeur y Bégin, 2005, citados por Rodríguez Toranzo y Delgado García, 2015, p. 97). Esta afirmación se produce por ser, la educación emocional, un proceso que puede tener múltiples influencias durante todo el proceso educativo y que, además, está muy ligado con la relación interpersonal (Rodríguez Toranzo y Delgado García, 2015). Pero no por ello, debemos dejar olvidadas las etapas posteriores a la Primaria: se debe trabajar siempre.

Con este trabajo se ha podido no solo contrastar, sino también valorar, la gran importancia que tiene la Educación Emocional desde temprana edad. Esto lo podemos confirmar tras observar que un porcentaje significativo de alumnos de Educación Primaria de la muestra analizada presentan dificultades en la denominación de ciertas emociones. Utilizan adjetivos para referirse a la emoción o confunden conceptos. Un ejemplo de ello lo encontramos en la emoción alegría, denominada en algunos casos como alegre o contento, haciéndose más notorio en las edades inferiores.

Por todo esto y mucho más, resulta tan relevante conocer qué es lo que está ocurriendo y qué es susceptible de mejora en el sistema educativo español para que la evolución temporal de la Inteligencia Emocional sea más notoria entre los estudiantes de diferentes edades de forma y manera que pudieran crecer y enriquecerse con las posibilidades que ésta brinda.

En definitiva, como profesionales nos corresponde despejar parte de estas incógnitas y ofrecer soluciones eficientes y eficaces con la mayor premura posible.

\section{REFERENCIAS BIBLIOGRÁFICAS}

Bisquerra, R. (2009). Psicopedagogía de las emociones. Madrid: Síntesis.

Bisquerra, R. (2011). Educación Emocional. Padres y Maestros, 337, 5-8.

Bisquerra, R. (2016). Educación Emocional: Propuestas para educadores y familias (3ª ed.). Bilbao: Editorial Desclée De Brouwer.

Domínguez Ramos, J. (2017). Educación Emocional para la resolución de conflictos en la escuela: Una aproximación desde la educación social. Intervención Psicosocioeducativa en la Desadaptación Social, 10, 11-22.

Froufe Quintas, S. (1990). Familia, escuela y valores sociales. Revista de Pedagogía de la Universidad de Salamanca, 3, 111-118.

Palomero, J. M. (2005). La Educación Emocional, una revolución pendiente. Revista Interuniversitaria de Formación del Profesorado, 19, 9-13.

Palacios, Y. (2010). Educación emocional y creatividad en la I y II etapa de Educación

Básica. Universidad Pedagógica Experimental Libertador, 34 (71), 249-270.

Petrus, A. (2004). Educación social y educación escolar. Pedagogía Social. Revista Interuniversitaria, 11, 87-110.

Reyes, A. (2016). 6 diferencias entre emociones y sentimientos. Recuperado de: http://www.psicoemocionat.com/1/post/2016/nov/6-diferencias-entre-emociones-y-sentimientos.html

Rodríguez Toranzo, B. y Delgado García, M. (2015). Una aproximación Teórica a la educación emocional en Primaria. En I Congreso Internacional de Expresión y Comunicación Emocional. Prevención de Dificultades Socioeducativas. 2-4 de septiembre de 2015 (pp. 95-105). Sevilla: CIECE.

\section{NOTAS}

1 Ítems basados en: Escuela de padres. (2018). Recuperado de: https://www.educapeques.com/escuela-depadres/inteligencia-emocional.html 